\title{
Geoprocessamento na caracterização da qualidade das águas na região de Natal e suas relações com doenças de veiculação Hídrica
}

\author{
Reinaldo Anatonio Petta, Ludmagna Pereira de Araújo, Paulo de Resende Nascimento \\ Depto de Geologia UFRN - Programa de Pós-Graduação em Geociências \\ Campus Universitário - Natal/RN CEP: 59072-970 \\ petta@geologia.ufrn.br - (084) 3215-3808
}

\begin{abstract}
This document presents the results of the geoprocessing evaluation of the straight relationships between water quality in Natal City and the main water diseases. The evaluation of the investigated parameters was accomplished through a "Water Management System" - GIS-WMS, which aimed to combine data about groundwater and surface water resources with the pollutant sources in Natal, and visualize its spatial distribution. From documents and data collected in public agencies and generated in loco, a database was set up with several information inherent to the sampled points. The material, including photographs, profiles and data of wells and other services, was associated to several thematic maps. Over this base, epidemiological data achieved at the municipal offices, were crossed with water quality and environmental data, enabling an analysis of the current context of the hydro system, allowing a future monitoring and management of the water quality in Natal. The main diseases considered were stomach cancer, cholera, amebic and bacillary dysentery, typhoid and paratyphoid fever, giardiasis, infectious hepatitis, leptospirosis and poliomyelitis.
\end{abstract}

Keywords: Geographic Information System, Remote Sensing, Public Health, Environmental management, Water Resources. 


\section{INTRODUÇÃO}

Natal tem passado por um processo de forte crescimento desorganizado nestes últimos 15 anos. Antigamente quando um turista ou morador abria a torneira da sua residência, do hotel ou da pousada, se deparava com uma água com qualidade de água mineral. Hoje, a situação está bem diferente. Desde o início do século passado, todo o esgoto produzido na cidade (somente 17\% saneada) é lançado 'in natura' no Rio Potengi, ou então é armazenado em fossas sépticas e "sumidouros" dos quintais das casas, afetando por percolação diretamente no lençol freático, de onde são retirados mais de $70 \%$ da água que abastece a cidade. Soma-se a este fato a impermeabilização do solo e a cobertura asfáltica que faz com que boa parte da água da chuva que serviria para recarga do aqüífero, seja escoada para o mar. Não se tem controle sobre o número de fossas e poços clandestinos existentes na cidade, porém a estimativa é de que, a cada ano, apenas a capital do Rio Grande do Norte jogue cerca de 42 milhões de metros cúbicos de esgoto nesse imenso filtro natural, denominado Sistema Aqüífero Dunas/Barreiras, porém há indícios de que esse número possa ser bem maior.

A conseqüência direta desse comportamento, que faz com que o lençol freático receba mais esgoto e menos água a cada ano, pode ser percebida nos diversos estudos realizados pela Universidade Federal do Rio Grande do Norte (UFRN), por ONGs e até mesmo pela Companhia de Águas e Esgotos do Rio Grande do Norte (CAERN). Hoje, o Sistema Aqüífero Dunas/Barreiras (lençol freático) está quase totalmente poluído. Em alguns pontos de captação, a quantidade de nitrato (um subproduto da contaminação por coliformes fecais) é de 100 ppm (partes por milhão). Ou seja, está bem acima dos 45 ppm considerados aceitáveis pela Organização Mundial da Saúde.

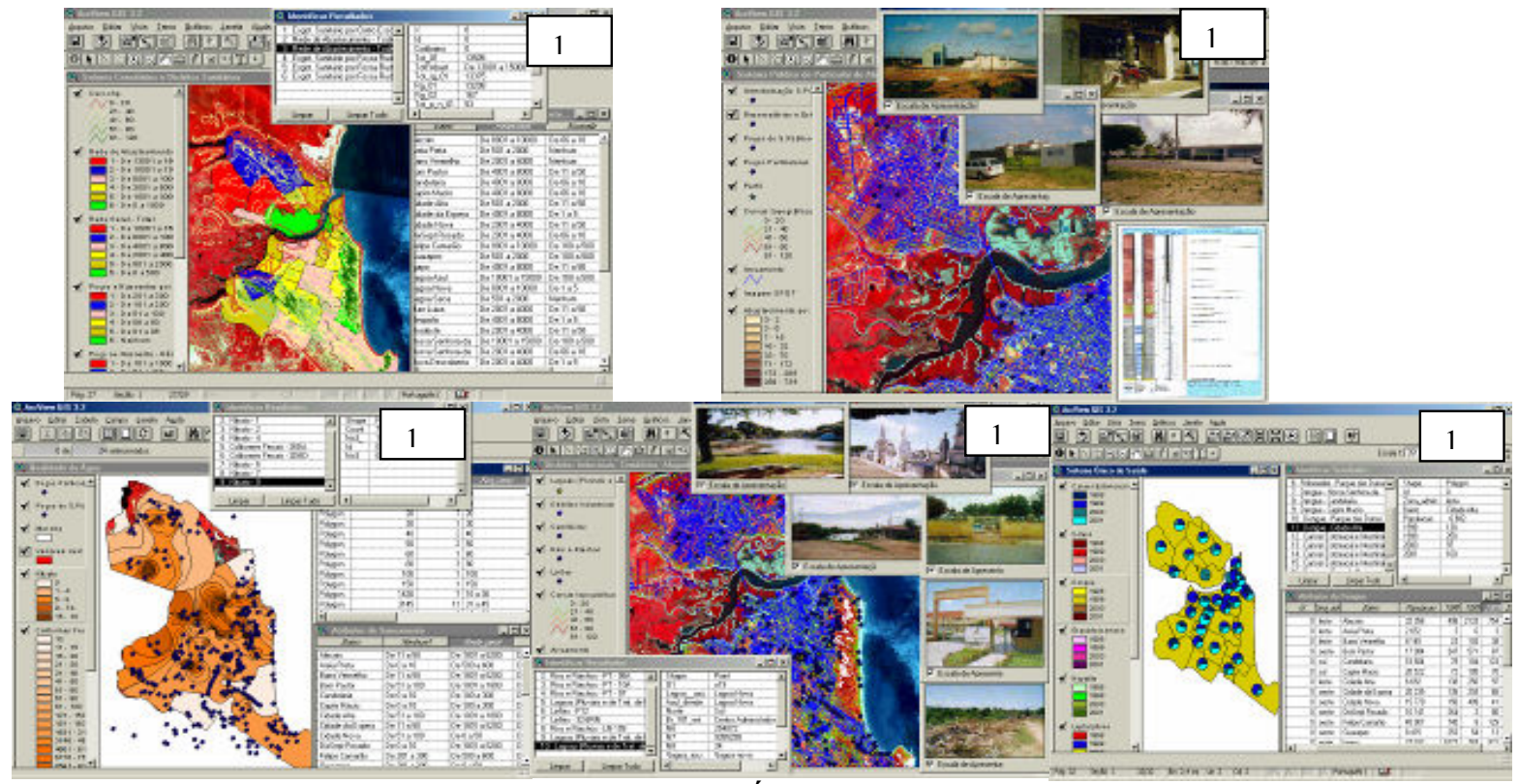

Figura 1 - O Sistema de Gerenciamento das Águas está composto por cinco temas principais: os quais abrangem dados do IBGE (1.1); Sistema de Abastecimento Público e Particular (1.2); da Qualidade da Água (1.3); dos Cemitérios, Distritos Industriais, Lagoas, Alagados e Lixões (1.4); da Secretaria Municipal de Saúde (1.5).

Existem diversos estudos e discussões sobre captação, efluentes, qualidade e contaminação da água em Natal, entretanto este que discutiremos aqui é pioneiro nesta área de vincular as estatísticas de distribuição de doenças transmitidas por meio hídrico e a qualidade das águas desta região. 
Nossa proposta pretende demonstrar a aplicação de um Sistema de Informações Geográficas SIG, funcionando como uma ferramenta de apoio, que possibilite complementar a ação dos programas de monitoramento e gerenciamento da qualidade da água, permitindo que a informação seja analisada de forma georreferenciada no espaço geográfico, com um grau de precisão quase sempre satisfatório, tornando-o uma alternativa viável, fácil de implementar e barata para levantamentos envolvendo eventos deste tipo.

A elaboração de um "Sistema de Gerenciamento das Águas" - SGA, permitiu identificar e caracterizar das diferentes fontes de poluição (industrial e doméstica) que influenciam direta ou indiretamente na qualidade das águas subterrâneas e de superfície (lagoas) na região de Natal e, possibilitará futuramente realizar o monitoramento e a gestão da qualidade da água nessa região. Este SGA oferece a oportunidade de se modelar integralmente em uma só plataforma, os principais problemas causadores de poluição do aqüífero que integra a bacia de Natal, à disponibilidade futura de recursos hídricos, e o gerenciamento relacional/espacial das doenças de veiculação hídrica (diarréia, hepatite, lepstopirose, dengue, cólera e outras). Uma vez que as metodologias empregadas para a análise dos possíveis riscos à saúde estão associadas ao seu consumo. Este sistema (Figura 1) está composto por camadas de informações sobre a contaminação hídrica do Município de Natal, visando considerar as questões relacionadas à vigilância e controle da qualidade da água.

\section{LOCALIZAÇÃO DA ÁREA}

O Município do Natal, capital do Estado do Rio Grande do Norte, situa-se na Zona Litorânea Oriental do Estado, na Subzona de Natal, a qual limita-se a Oeste com o Município de São Gonçalo do Amarante; ao Norte, com Extremoz; ao Sul, com Parnamirim; e a Leste, com Oceano Atlântico (

Figura 2), nas coordenadas geográficas aproximadas de $5^{\circ} 44^{\prime}$ 50” de Latitude Sul e 35 12 ' 34” Longitude Oeste.

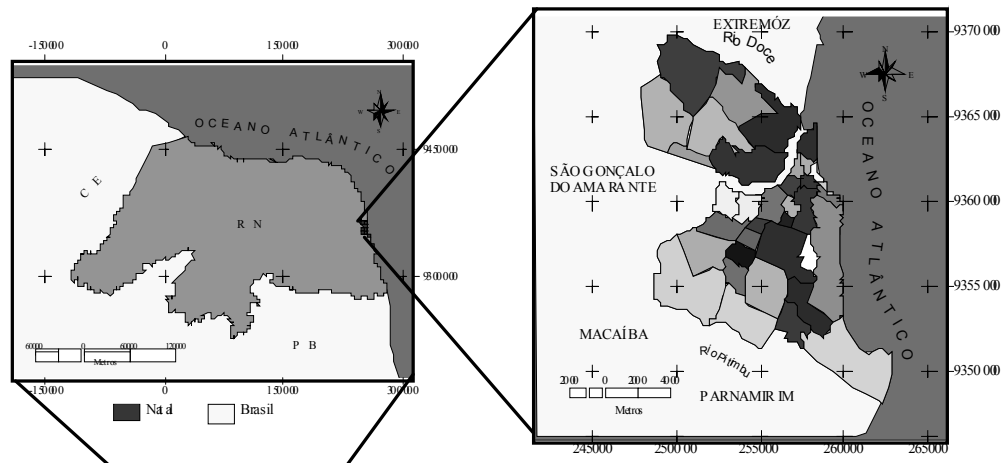

Figura 2 - Localização da área de estudo.

\section{METODOLOGIA}

Os trabalhos realizados pela Companhia de Águas e Esgotos do Rio Grande do Norte (CAERN) em parceria com a Universidade Federal do Rio Grande do Norte (UFRN) já permitiram identificar os principais focos de contaminação dos mananciais de águas superficiais e subterrâneas na região de Natal. São eles: (i) As fossas e sumidouros (conseqüências da falta de saneamento básico em toda a cidade); (ii) Lagoas de infiltração (decorrentes das ligações clandestinas de esgoto na rede de águas pluviais); (iii) Antigos cacimbões transformados em fossas (contaminam diretamente os lençóis de água subterrânea); (iv) Poços mal construídos (elaborados sem critérios técnicos adequados); (v) 
Lixões (construídos sobre as dunas, que são terrenos muito permeáveis); (vi) Esgotos industriais (transferidos para lagoas de infiltração ou despejados diretamente nos rios Potengi, Jiqui e Jundiaí); (vii) Postos de gasolina (vazamentos de combustível dos tanques enterrados no terreno e não-tratamento das águas servidas); (viii) Criações de animais (bovinos, suínos e aves) nas margens dos rios e lagoas e (ix) Desmatamentos das matas ciliares e ocupação indiscriminada das áreas de recarga do aqüífero.

Tabela 1 - Pontos cadastrados durante os trabalhos de campo.

\begin{tabular}{l|c}
\hline NOME DOS PONTOS DE CADASTRO & $\mathrm{N}^{\mathbf{0}}$ de Cadastros \\
\hline Setor Administrativo da CAERN & 38 \\
\hline Estações Elevatórias & 22 \\
\hline Reservatórios & 26 \\
\hline Poços do Sistema Público & 215 \\
\hline Rios e Riachos & 05 \\
\hline Principais Alagados & 05 \\
\hline Cemitérios & 10 \\
\hline Distritos Industriais & 12 \\
\hline Lagoas (Capt. Pluv. e Esg.) & 60 \\
\hline Lixões & 05 \\
\hline Poços Particulares & 202 \\
\hline Total do Cadastramento & 600 \\
\hline
\end{tabular}

Nosso objetivo principal foi levantar a localização e a distribuição espacial destas fontes poluentes (Tabela 1), elaborando mapas temáticos de diversos enfoques e relacionados a banco de dados que permitissem avaliar e quantificar as suas diversas influências na qualidade da água desta área.

Para a preparação das bases cartográficas, utilizaram-se programas como AutocadMap e o $\mathrm{R} 2 \mathrm{v}$, para a digitalização, montagem e atualização dos mapas topográficos, hidrográfícos, geológicos, geo-ambientais, litológicos entre outros. Para as diversas metodologias dos SIG, empregou-se o software ArcGis, da ESRI, sendo utilizada no caso, sua própria linguagem de programação para a elaboração do Modelo Digital de Terreno (MDT), mapa de cadastramento dos poços, entre outros mapas temáticos.

TEMA DOS RECURSOS NATURAIS: O mapa das quadras e lotes de Natal na escala de 1:2.000 foi obtido junto a CAERN. Foram utilizadas imagens do satélite SPOT para o mapeamento de alguns dos recursos hídricos, compostos por rios, riachos, açudes, lagoas, barragens, poços, públicos e particulares. Os dados compostos neste tema foram: geológico, geomorgológico, de uso e ocupação do solo, meio físico, zonas de proteção ambiental, metalogenético e topográfico.

TEMA DE SETORES CENSITÁRIOS E DISTRITOS SANITÁRIOS: Os contornos dos setores censitários - SC do município de Natal foram transcritos visualmente a partir da base de dados alfanuméricos do IBGE, para plantas na escala de 1:10.000 e 1:2.000 obtidas junto ao IDEMA/RN e a CAERN. A estes setores foram associados dados sobre saneamento, abastecimento e população contidos no Censo Demográfico de 2.000. Os layers do esgotamento sanitário foram classificados por domicílios particulares permanentes, se pela rede geral de esgoto ou pluvial, fossa séptica, por fossa rudimentar, valas, rio, lago ou mar, ou outro tipo de escoadouro, também se tinha ou não banheiro nem sanitário. As formas de abastecimento de água foram classificadas de acordo com os domicílios particulares 
permanentes sob o total dos usuários da rede geral; poço ou nascente; outra forma de abastecimento e não canalizada (Figura 1.1).

TEMA DO SISTEMA PÚBLICO E PARTICULAR DE ABASTECIMENTO DE ÁGUA: Este tema foi implementado a partir de cartas digitais na escala 1:2.000, obedecendo ao mapa cedido pela CAERN, envolvendo a identificação dos escritórios, dos reservatórios, poços públicos e particulares, estações de tratamento, elevatórias e seus respectivos dados alfanuméricos, assim como fotografias do referido ponto, locado pelo GPS e visualização dos perfis (no caso dos poços) escanerizados (Figura 1.2). Neste tema foram incorporadas as informações de análises nas concentrações de nitrato e a camada em 3D do não-saturado.

\section{TEMA DOS DISTRITOS INDUSTRIAIS, DOS CEMITÉRIOS PÚBLICOS e} PARTICULARES, DAS LAGOAS, ALAGADOS E DOS LIXÕES: A rotina utilizada foi à mesma que a anterior, a mesma escala (1:2.000), os pontos foram obtidos em campo com através da utilização do GPS. As imagens, por meio de fotografias e os dados alfanuméricos implementados são referentes ponto e informações complementares do mesmo (Figura 1.4).

TEMA DO SISTEMA ÚNICO DE SAÚDE: Nesta camada foram implementados dados sobre a incidência de doenças vinculadas ao saneamento nos bairros do município, expondo sua situação existente para cruzamento dos dados com os recursos hídricos, distritos industriais, cemitérios e lixões. Os dados estão dispostos no tema de várias formas, todos referentes aos anos de 1998 a 2001 (Figura 1.5).

TEMA DE QUALIDADE DA ÁGUA: Foram associados dados sobre o padrão admissível de acordo com os padrões a OMS, CONAMA, CAERN e SERHID, no sentido que cada ponto tenha seu posicionamento espacial localizado e plotado como ponto permanente de monitoramento, em cartas com escala 1:2.000 fornecido pela CAERN (Figura 1.3).

\section{ANÁLISE DOS RESULTADOS}

A análise espacial (da) de distribuição das fontes poluentes e suas relações com a saúde pública, teve como objetivo principal identificar áreas e as populações submetidas a risco utilizando-se os critérios ambientais e sócio-demográficos, sendo de vital importância para apoiar o processo de análise utilizando-se o sistema elaborado.

A Tabela 2 identifica exemplos de possíveis populações e áreas submetidas a risco segundo os critérios citados. Os dados foram tabulados a partir dos dados do censo 2.000 e da CAERN, OMS e CONAMA, e as áreas de cada região foram calculadas diretamente no SGA. O último censo identifica uma população de 712.317 habitantes para a cidade de Natal.

Para facilitar melhor a identificação das diversas informações, as variáveis foram agrupadas em classes, que variaram de 4 a 6 a depender do caso. As áreas de ocorrência dos fatos foram classificadas respectivamente, da maior para a menor categoria, dos tons cinza mais escuros aos claros entremeados com hachuras. As respectivas figuras referentes a cada um dos temas explorados e analisados através do sistema, se encontram a seguir.

Áreas de maior número de residentes, segundo o censo de 2.000, que declararam não ser supridos por rede geral de abastecimento de água (Figura 3 ).

Áreas de maior concentração em fossas sépticas e/ou rudimentares e maior número de poços. Devido a crescente população destes bairros é possível que haja contaminação do aqüífero. Estes foram identificados de acordo com a base de dados do setor censitário que respondiam a este critério (Figura 4). 
Áreas de concentração do íon Nitrato, superior ao índice aceitável pelo CONAMA e OMS entorno dos poços que apresentam teores acima de $40 \mathrm{mg} / \mathrm{l}$. Os teores foram localizados por meio de buffers de $0,5 \mathrm{~km}$ entorno dos arcos que representam toda a rede de abastecimento (Figura 5).

Áreas de maior incidência, para todos os casos de morbidade, em tons cinza escuro. Neste caso associou-se a malha hídrica provável. As áreas foram identificadas por meio da base de dados da SMS (Figura 6).

Tabela 2 - Localização, população residente e área de risco, de acordo com os critérios de qualidade da água.

\begin{tabular}{|c|c|c|c|c|}
\hline & $\begin{array}{l}\text { Critério de } \\
\text { risco }\end{array}$ & $\begin{array}{l}\text { Pop. } \mathrm{n}^{\mathrm{o}} \mathrm{de} \\
\text { residentes }\end{array}$ & $\begin{array}{l}\text { Área } \\
\left(\mathrm{km}^{2}\right)\end{array}$ & Localização \\
\hline 1. & $\begin{array}{l}\text { Uso de fontes } \\
\text { alternativas } \\
\text { de } \mathrm{H}_{2} \mathrm{O}\end{array}$ & 1.272 & 11,35 & $\begin{array}{l}\text { Zona Norte - Nsa Sra da Apresentação seguida } \\
\text { por Felipe Camarão, Zona Oeste com } 593 \\
\text { residências. }\end{array}$ \\
\hline 2. & $\begin{array}{l}\text { Uso poços ou } \\
\text { nascentes }\end{array}$ & 247.440 & 70,01 & $\begin{array}{l}\text { Zona Sul - Ponta Negra, Capim Macio, } \\
\text { Candelária e Lagoa Nova. } \\
\text { Zona Norte - Pajussara, Lagoa Azul e Nsa Sra } \\
\text { da Apresentação. } \\
\text { Em seguida Redinha e Potengi - Zona Norte, } \\
\text { Petrópolis, Alecrim e Tirol - Zona Leste, } \\
\text { Felipe Camarão - Zona Oeste, Nova } \\
\text { Descoberta, Extremoz e Neópolis - Zona Sul. }\end{array}$ \\
\hline 3 & $\begin{array}{l}\text { Contaminaçã } \\
\text { o da água } \\
\text { (Nitrato) }\end{array}$ & 6.434 & 4,19 & $\begin{array}{l}\text { Zona Sul - Neópolis e, } \\
\text { Zona Leste - Praia do Meio. Seguido de Lagoa } \\
\text { Azul e Igapó - Zona Norte, Alecrim - Zona } \\
\text { Leste e Sul - Lagoa Nova, Nova Descoberta e } \\
\text { Pitimbu. }\end{array}$ \\
\hline 4 & $\begin{array}{l}\text { Incidência de } \\
\text { casos em } \\
\text { morbidade }\end{array}$ & 236.707 & 105 & $\begin{array}{l}\text { Zona Norte e Oeste. Entorno do Rio Potengi, } \\
\text { Complexo do Rio Doce, Lagoa de Extremoz e } \\
\text { periféricas. }\end{array}$ \\
\hline
\end{tabular}

A Tabela 2 apresenta os critérios que foram utilizados, de modo a permitir a identificação de grupos sócio-espaciais sujeitos a riscos à saúde associados aos recursos de abastecimento de saneamento. $\mathrm{O}$ uso de fontes alternativas de abastecimento de água por meio de pequenos mananciais locais (critério 1) na Figura 3, ou o uso poços ou nascentes em áreas de maior concentração em fossas sépticas e/ou rudimentares (critério 2) visualizado na Figura 6, podem apresentar riscos para parcelas significativas da população (cerca de 35\%), situadas nas regiões Norte e Sul do município das mais diversas classes econômicas. Os teores nas concentrações de nitrato encontram-se distribuídos por todo o município, como mostra as manchas da obtido a partir de dados de todos os poços (Figura 5). Foram associados a esses teores (critério 3) para os casos de mortalidade em câncer estomacal e intestinal e pode-se observar que a população sob risco (menos que 2\%), concentra-se na zona Sul e Leste.

A localização da população residente e área de risco para as incidências dos casos de morbidade (critério 4) segundo dados obtidos Secretaria Municipal de Saúde podem ser visualizados na (Figura 6). Abrange uma grande parte da população sob risco, representando mais de 30\% da população total de residentes no município. As áreas de incidências dos casos de morbidade estão concentradas no entorno do Rio Potengi, do Complexo do Rio Doce, Lagoa de Extremoz e periféricas da Zona Norte e Oeste, as quais representam uma malha hídrica diversificada. 


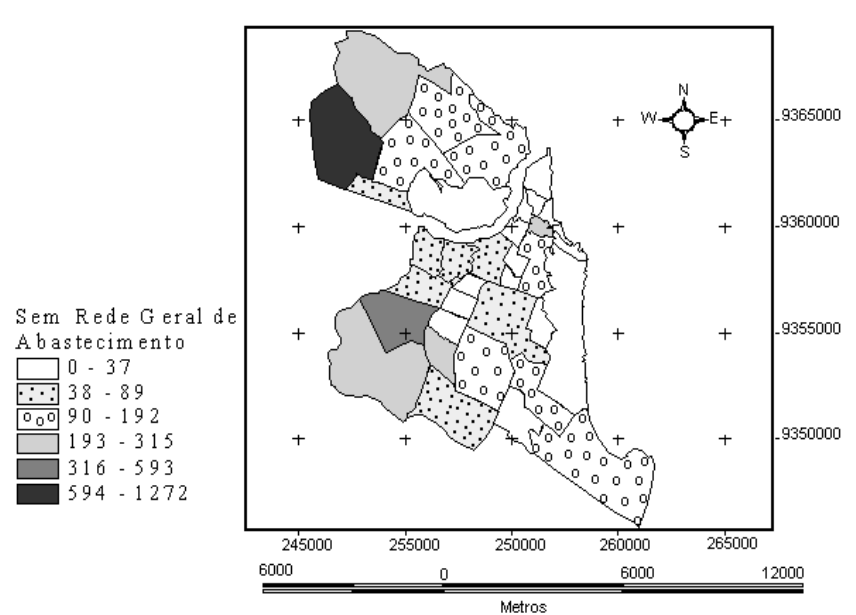

Figura 3 - Áreas de acordo com número de residentes não supridos pela rede geral de abastecimento de água, segundo o censo de 2.000. Maior concentração foi identificada em hachuras de tom cinza escuras.

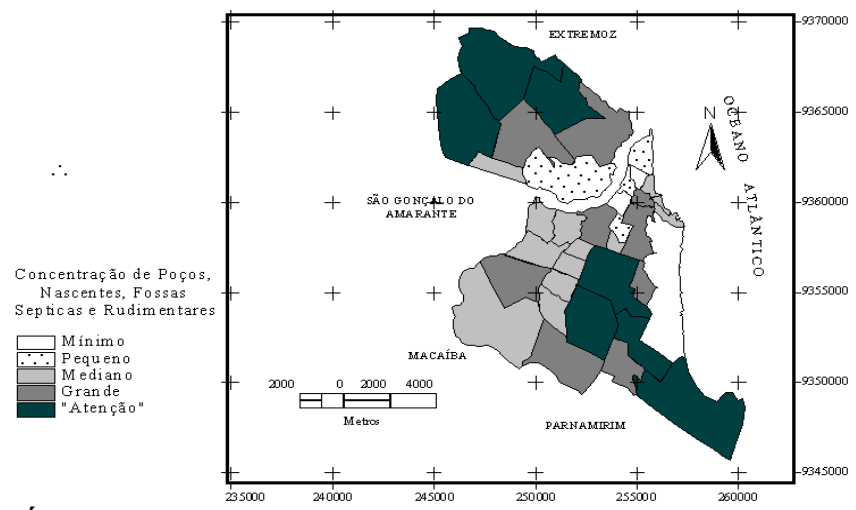

Figura 4 - Áreas de maior concentração em fossas sépticas elou rudimentares e maior número de poços. Estes foram identificados de acordo com a base de dados do setor censitário que respondiam a este critério. As hachuras de tom cinza escuro mostram os bairros sob risco em relação à qualidade da água.

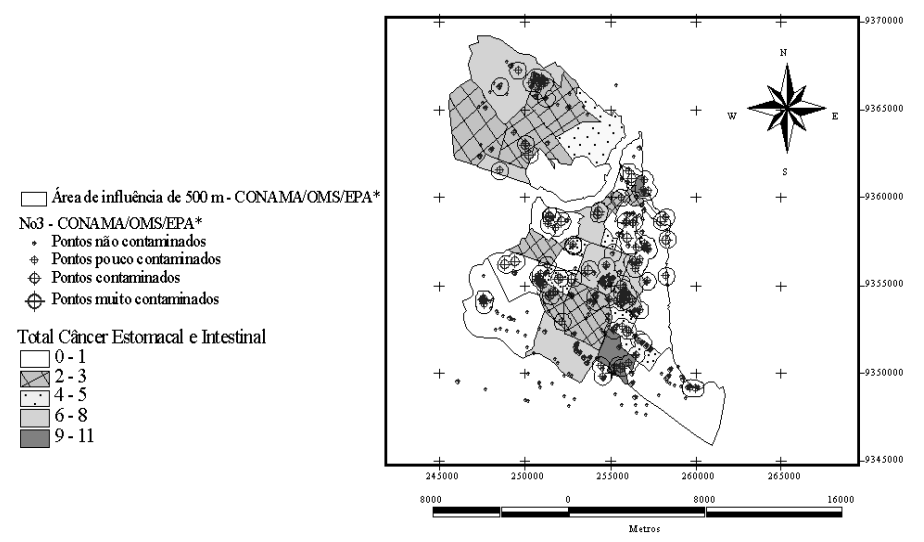

Figura 5 - Contaminação por nitrato nos poços públicos e particulares em Natal. A análise espacial utilizou a técnica de buffers em um raio de $500 \mathrm{~m}$ a partir dos postos com teores de nitrato acima dos níveis admissíveis pelos órgãos CONAMA/OMS. Esses dados foram cruzados com os dados de mortalidade em cânceres estomacal e intestinal. 

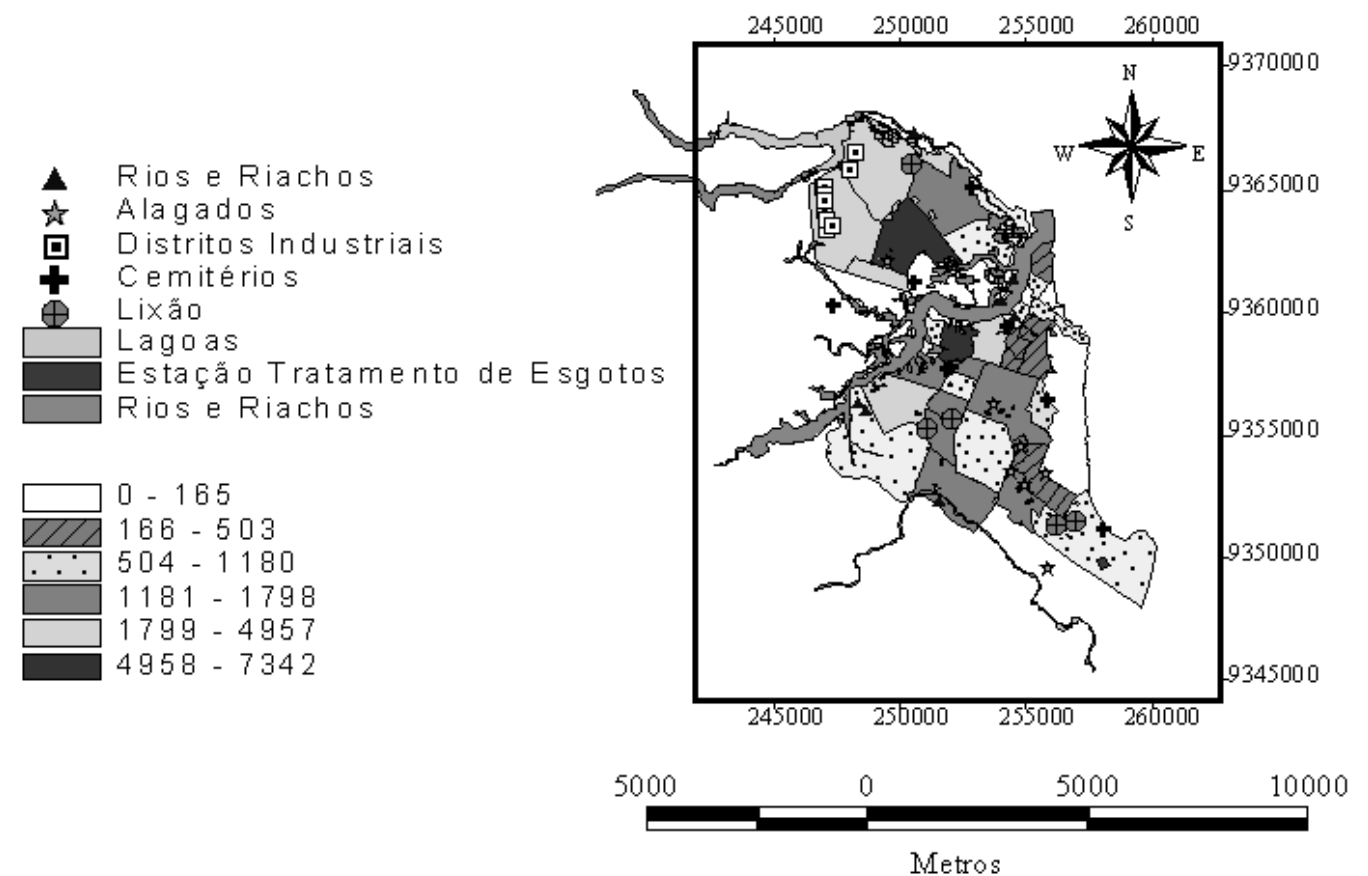

Figura 6-Áreas de maior incidência dos casos de morbidade, para todos os casos estudados, em hachuras de tom cinza escuro. Neste caso associou-se a malha hidrica provável.

\section{CONCLUSÕES}

Buscou-se com esse trabalho implementar uma base hidro-cartográfica digital da região de Natal, com dados confiáveis e que resgatasse o maior número de informações possíveis, pois somente um monitoramento extenso e sistemático, estabelecendo-se técnicas de controle das fontes poluidoras e a identificação dos riscos à saúde humana relacionados ao não atendimento do padrão de potabilidade da água, permitirá que se tomem precauções e se estabeleçam políticas de controle dos padrões da qualidade das águas. Desta forma, o SGA dá oportunidade de se modelar integralmente em uma só plataforma, os principais problemas causadores de poluição do aqüífero Dunas/Barreiras, com enfoque aos problemas do binômio "água \& saúde", como também de criar simulações visando identificar áreas de risco, assim como avaliar as relações de qualidade da água com a saúde pública, gerar de novos mapas temáticos identificadores de áreas problemáticas com focos epidemiológicos, que advertem problemas relacionados à má qualidade da água.

Neste ponto pode-se avaliar que a região de Natal carece de um gerenciamento intensivo em muitas áreas, principalmente naquelas localizadas em zona de recarga do aqǘfero assim como, com urgência, um saneamento adequado para evitar a poluição do mesmo. Verificou-se também a necessidade de uma política intensiva de saneamento em áreas vulneráveis a poluição, onde as pesquisas devem vir acompanhadas de outras ações, como a finalização do sistema de coleta e tratamento de esgoto em toda a cidade, a criação de uma política e até de leis que viabilizem uma recarga melhor do aqüífero, o cadastramento dos poços existentes, a proibição da construção de novos poços e, principalmente, a criação de uma equipe de fiscalização para a utilização dos recursos hídricos (atualmente, a SERHID conta apenas com dois fiscais para todo o Estado e a conscientização da população sobre o problema. 


\section{REFERÊNCIAS BIBLIOGRÁFICAS}

Araújo, L. P.; Petta, R. A.; Duarte, C. R.. (2004) Sistema de informações geográficas aplicado à análise das relações da qualidade da água e risco em saúde pública no município de Natal (RN). Geociências, 2004.

Barcellos, C. e Pina, M. de F. 1998. Análise de risco em saúde utilizando GIS: o caso do abastecimento de água no Rio de Janeiro. Revista FatorGis, São Paulo e no site URL: http://www.procc.fiocruz.br/ barcello/

Carvalho Jr. E. R. 2001. Contaminação das águas subterrâneas por nitrato e sua relação com a estrutura hidrogeológica nos bairros de Pirangi e Ponta Negra, Natal/RN. Dept ${ }^{\circ}$ Geologia, Universidade Federal do Rio Grande do Norte, Natal, dissertação de mestrado, 170p.

Petta, R. A. ; Araújo, L. A. ; Lima, R. F. S. ; Duarte, C. R. (2006). Avaliação da contaminação da água consumida no campus da UFRN em relação à presença de nitratos provenientes de fossas sépticas. In: Silva, C.R.; Figueiredo, B.R.; De Capitani, E.M.; Cunha, F.G.. (Org.). Geologia Médica no Brasil: Efeitos dos materiais e fatores geológicos na saúde humana e meio ambiente.. Rio de Janeiro, RJ: CPRM, 2006, v. , p. 192-202.

Petta, R. A. ; Meyer, M.; Lima, R. F. S. (2006) Gis for evaluation of the nitrate water contamination and incidence of cases of mortality in Natal (NE Brazil) In GIS \& Remote Sensing - Gottingen GGRS- Ed. Erasmi, S.; Cyffka, B.- Gottingen, Alemanha, www.uni-goettingen.de/en/sh/36647.html pg.321 - 332. Ed. Martin Kappas, Christoph Klein \& Branislav Sloboda ISBN 978-3-938616-93-2 